\title{
Research
}

\section{Linking Resilience Theory and Diffusion of Innovations Theory to Understand the Potential for Perennials in the U.S. Corn Belt}

\author{
$\underline{\text { Ryan C. Atwell }}^{1}, \underline{\text { Lisa A. Schulte }}^{1}$, and Lynne M. Westphal $^{2}$
}

\begin{abstract}
In the last $200 \mathrm{yr}$, more than $80 \%$ of the land in the U.S. Corn Belt agro-ecosystem has been converted from natural perennial vegetation to intensive agricultural production of row crops. Despite research showing how re-integration of perennial vegetation, e.g., cover crops, pasture, riparian buffers, and restored wetlands, at strategic landscape positions can bolster declining regional ecosystem functions, the amount of land area devoted to row crop production in the Corn Belt continues to increase. As this region enters a time of fast-paced and uncertain reorganization driven by the emerging bioeconomy, changes in land use will continue to take place that will impact the resilience of the Corn Belt's linked social and ecological systems for years to come. Both resilience theory and the diffusion of innovations theory investigate how change is brought about in systems through the adaptation and innovation of social actors. In this paper, we integrate these two frameworks in the analysis of 33 in-depth interviews to improve our understanding of how rural Corn Belt stakeholders make conservation decisions in the midst of an uncertain future. Interview data indicate that the adoption of conservation practices is based not only on immediate profitability but also on the interplay between contextual factors at three distinct levels of the system: compatibility with farm priorities, profitability, practices, and technologies; community-level reinforcement through local social networks, norms, and support structures; and consistent, straightforward, flexible, and well-targeted incentives and regulations issuing from regional institutions. Interviewees suggest that the multiscale drivers that currently support the continued expansion of row crop production could be realigned with conservation objectives in landscapes of the future. Adaptation of social actors through collaborative learning at the community level may be instrumental in brokering the sort of multiscale system change that would lead to more widespread adoption of perennial cover types in the Corn Belt.
\end{abstract}

Key Words: adaptive co-management; agriculture; Iowa; learning; nonpoint source pollution; restoration; scale; social-ecological systems; row crops; Corn Belt

\section{INTRODUCTION}

Change is both a disruptive and a renewing force in natural and human systems (Gunderson and Holling 2002, Walker et al. 2006). When change is driven by collective human decision making, its ramifications can be very difficult to predict because many plausible courses of action may be chosen. In natural resource management, the dynamic decisions of social actors often heighten the difficulty involved in addressing what are already complex ecological questions.

This is the case in agro-ecosystems of the northcentral U.S. Corn Belt, a region with a long history of change based on the interplay of natural processes and the decisions of its human inhabitants (Axelrod 1985). This region is currently undergoing a period of rapid and uncertain reorganization driven by the increased demand for bioenergy crops (Hinkamp et al. 2007). Despite the ecological and social deficits associated with agricultural intensification, the amount of land devoted to row crop production is continuing to increase in response to commodity markets, public policies, cultural norms, and farmer decisions (Secchi et al. 2008). Although the problems inherent in this trajectory are recognized (Duffy 2006, EPA 2007), it is unclear how they might be addressed in the midst of an uncertain future. 
Resilience theory (Gunderson and Holling 2002) and diffusion of innovations theory (Rodgers 2003) are two interdisciplinary avenues of inquiry that focus on how human decision making can influence, and be influenced by, the process of change. Resilience theory is rooted in the ecological sciences, is in its theoretical adolescence, and is currently receiving widespread attention from and being applied by scientists and practitioners from diverse fields (Liu et al. 2007). Resilience theory is also receiving criticism in some quarters because of its weak integration and appropriation of social science theory and methodologies and because it oversimplifies complex problems to incorporate complex social phenomena as quantifiable variables in systems models (Harrison 2003, Jannsen et al. 2006, Christensen 2008). In contrast, diffusion of innovations theory is well established and based on more than $60 \mathrm{yr}$ of empirical research, including both qualitative and quantitative studies (Rodgers 2003). However, in the last two decades, the momentum of this field has dissipated because questions for future study demand foci and methodologies different from those of past diffusion research, including a greater understanding of the sort of multilevel and ecological system drivers that are the focus of resilience theory (Fliegel and Korsching 2001, Wejnert 2002, Rodgers 2003).

We have found resilience theory and diffusion of innovations theory to be complementary explanatory packages that, when taken together, allow us to rigorously probe how rural stakeholders in the Corn Belt make decisions that affect conservation outcomes. Here we use these two frameworks in the analysis of data from in-depth interviews. We posit that, together, these theories work to explain how sociocultural context constrains, or enhances, the adoption of conservation practices by rural stakeholders.

\section{Dysfunction in the Corn Belt}

In their attempts to optimize one or more components of a complex system, humans often dampen the natural variability and resilience of other components (Gunderson and Holling 2002, Walker et al. 2006). Such is the case in the northcentral U.S. Corn Belt, in which attempts to optimize agricultural production by controlling other key system variables such as commodity crop markets, nutrient levels, herbicide and pesticide application, surface water removal, wetland drainage, and stream channelization have led to the loss of dynamic system characteristics over time, e. g., natural pest and flood control, diversified farming systems, rural commerce and population, water purification (Keeney and Kemp 2002, Schulte et al. 2006, Nassauer et al. 2007).

In the last decade, the ecological imbalance in the Corn Belt has become a problem of national priority. High levels of nutrients, e.g., nitrogen and phosphorous, associated with agriculture in the region's rivers have been implicated as the primary drivers of the hypoxic dead zone downstream in the Gulf of Mexico (EPA 2007, Nassauer et al. 2007). Recent research shows that the increasing nitrate levels in the contributing rivers are best explained by a decrease in the amount of perennial crops and pasture in agricultural watersheds over the last several decades (Hatfield et al. 2008). These trends are expected to continue into the near future with the emergence of corn-based ethanol (Secchi et al. 2008), although in the long term the emerging bioeconomy (Hinkamp et al. 2007) may present opportunities for system reorganization.

Agricultural intensification has also been linked with regional social dysfunction. From 1950 to 2002 , the portion of revenue from the sale of agricultural products that was returned to farmers decreased from $37 \%$ to $19 \%$, while farm input costs increased sevenfold and the real price of corn decreased fivefold when adjusted for inflation (Duffy 2006). The region is losing once numerous, mid-sized, owner-operated farms, while large and corporate farms owned by outside investors are increasing in number and size. Although the federal government spent more than U.S. \$2.2 billion in 2005 in the state of Iowa alone on U.S. Department of Agriculture (USDA) agricultural support programs (EWG 2006), and nearly $40 \%$ of the income of regional corn and soybean farms comes from government payments, much of this funding benefits "absentee" farm owners rather than local operators or rural communities (Duffy 2006).

Research suggests that the restoration of perennial vegetation within relatively small portions (5-15\%) of the rural Corn Belt landscape may disproportionately benefit the region's long-term ecological and social resilience (Schulte et al. 2006, Nassauer et al. 2007). Such perennial conservation practices may include the use of cover crops, pastures, well-managed multispecies riparian buffers and wetlands, and concentrated areas of 
remnant and restored forest and prairie. However, with more than $95 \%$ of the land in the Corn Belt in private ownership (USDA 2002), conservation practices must be implemented by farm owners, operators, and rural residents across property boundaries if landscape-scale objectives such as clean water are to be achieved. At the present time, perennial conservation practices are neither a rural priority nor well integrated into rural culture (Atwell 2008).

\section{Resilience, scale, adaptation, and innovation}

Resilience theory emphasizes that ecological and social systems are inextricably linked and that their long-term health is dependent upon change, including periods of both organization and growth, as well as periods of collapse and reorganization (Gunderson and Holling 2002, Walker et al. 2006). It is proposed that the complexity inherent in dynamic social-ecological systems often hinges upon the interaction of the relatively small number of three to six critical variables and processes that operate over distinctly different spatial and temporal scales (Gunderson and Holling 2002). In addition to space and time, sociological conceptions of scale also consider how humans symbolize reality at different organizational levels (Pritchard and Sanderson 2002, Westley et al. 2002, Cumming et al. 2006). The innate human tendency to create meaning gives us the ability not only to construct the landscape through implicit social norms and explicit group discourse but also to manipulate its future cycles through management and technological initiatives.

For this reason, human adaptation is an essential component in the resilience of complex socialecological systems, and resilience theorists have called for a pragmatic approach to understand "where resilience resides in the system, and when and how it can be lost or gained" (Walker et al. 2002:3). This includes identifying "roadblocks and opportunities for adaptive capacity and innovation" (Pritchard and Sanderson 2002:166), as well as "points of intervention where one can increase resilience of desired configurations to future changes, including those that are unforeseeable" (Walker et al. 2002:3). Resilience theory highlights the adaptability of human social actors whose collective choices and behaviors can erode or bolster system resilience or transform a system into a more or less resilient state (Gunderson and Holling 2002, Walker et al. 2006). Resilience theory suggests that key system components, and the focal scales at which they interact, are often best identified through strategies that partner experts with stakeholders who understand the system from different scales and perspectives (Walker et al. 2002, Westley et al. 2002).

Diffusion of innovations theory is a field of research that investigates how new ideas spread in a populace (Rodgers 2003). This theory emerged in the mid-20th century from studies in several disciplines, including seminal studies on the adoption of agricultural production technologies for row crops by Corn Belt farmers (Ryan and Gross 1943). Research and theory on the diffusion of innovations indicates that most people decide to adopt an innovation based primarily on subjective values and social norms diffused through interpersonal networks, rather than as a result of rational reflection on scientific data (Ryan and Gross 1943, Coleman et al. 1957, Rodgers 2003). The example set by opinion leaders, who often have connections both inside and outside of a local community, can serve to broker adoption across societal boundaries (Burt 1999, Rodgers 2003). Because diffusion of innovations theory has a long history of research in the Corn Belt, it may offer key insights into how perennial conservation practices can be integrated into production systems for row crops through adoption by farmers in privately owned working landscapes.

Current diffusion research investigating conservation practices has been largely built on retrospective, survey-based studies that link the timing of innovation adoption with social and demographic data (Fliegel and Korsching 2001, Wejnert 2002, Rodgers 2003). However, because diffusion is a social phenomenon and because not all innovations are successfully diffused or found to be beneficial in their cultural contexts, it has been widely suggested that "positioning research" to understand the efficacy of potential innovations is needed (Fliegel and Korsching 2001, Wejnert 2002, Rodgers 2003). These theorists also posit that such research might use either qualitative or systems approaches, such as those used in many resilience studies, to understand the interplay between multiscale drivers of change, which are often difficult to quantify and compare directly. Our research uses such an approach to understand the sociocultural efficacy of, and potential for, increasing perennial vegetation in Corn Belt agroecosystems. 
In this study, we evaluated how adoption of perennial conservation practices by rural stakeholders in Corn Belt landscapes is constrained or enhanced by social and ecological factors at multiple scales. Our study questions included:

1. Why and how would farmers adopt practices that increase perennial vegetation on their landscapes?

2. What factors stand in the way of adoption?

3. How can restoration strategies be most effectively disseminated within the multiscalar social-ecological context of the rural Corn Belt?

\section{METHODS}

\section{Study area}

Our study area (Fig. 1) is an agricultural community encompassing the headwaters of three small watersheds that roughly coincides with the western half of the South Skunk School District and surrounds the rural town of Stanhope, Iowa (Atwell 2008). Stanhope lies in Hamilton County in central Iowa, which is in turn situated in the Des Moines Lobe, an ecoregion of the Corn Belt that has been identified as contributing disproportionately to hypoxia in the Gulf of Mexico (EPA 2007) because of the high incidence of underground field drainage networks. Hamilton County is one of 15 Iowa counties located entirely within the Des Moines Lobe and is representative of this ecoregion in its high preponderance of row crop agriculture, high levels of concentrated animal production facilities, consolidation of agriculture into large farms, loss of farmers, and increase in nonfarm rural residents (Table 1). All three of the watersheds within our study site are currently targeted by research and management initiatives whose aim is to better understand and influence the interplay between agricultural intensification, ecosystem services, and rural social vitality.

\section{Sampling strategy}

The goals of our research were to understand how shared values and norms influence collective behavior. We used nonprobability sampling techniques (Handwerker 2005), which are common in qualitative and cultural research, to study in greater depth a smaller number of cases that are particularly relevant to our study questions. In this way, our aims and methods differ from those of quantitative studies in which a representative sample is drawn from a large number of cases to generalize to a broad population. As is common in qualitative research, we did not choose our sample size beforehand but worked inductively and systematically toward "theoretical saturation" (Neuman 2003), the point at which enough cases were explored to thoroughly elucidate the questions and concepts under investigation.

We used a multistage, nonprobability sampling design to choose interviewees (Handwerker 2005). Ethnographic techniques (Spradley 1979, Handwerker 2005) were used to gain entrance into our community of study, and informal conversations about our research were initiated with rural stakeholders during visits to local gathering places, e.g., churches, restaurants, farm supply cooperatives. We presented ourselves as researchers from Iowa State University studying how rural people value the places they live, with the goal of evaluating and recommending improvements to agricultural and conservation practices. Based on insights gained from discussions with residents of our study site, we used purposive sampling (Neuman 2003, Handwerker 2005) to choose the initial participants for in-depth interviews. They represented a diversity of local perspectives within the following overlapping groups: farm operators, farm owners, nonfarm rural residents, rural opinion leaders, and local conservation personnel. Among these groups, we gave priority to interviewing opinion leaders whose behavior, decisions, and influence were recognized by other community members as impacting sizable portions of the landscape (> 200 ha). Snowball sampling techniques, in which ongoing interviews and continued ethnographic work generated more interview contacts, were used to choose interview subjects who represented the above categories until we had reached theoretical saturation in relationship to major study questions. 
Fig. 1. Our study site is a rural agricultural community situated in the middle of the Des Moines Lobe ecoregion in southwest Hamilton County, Iowa, USA.

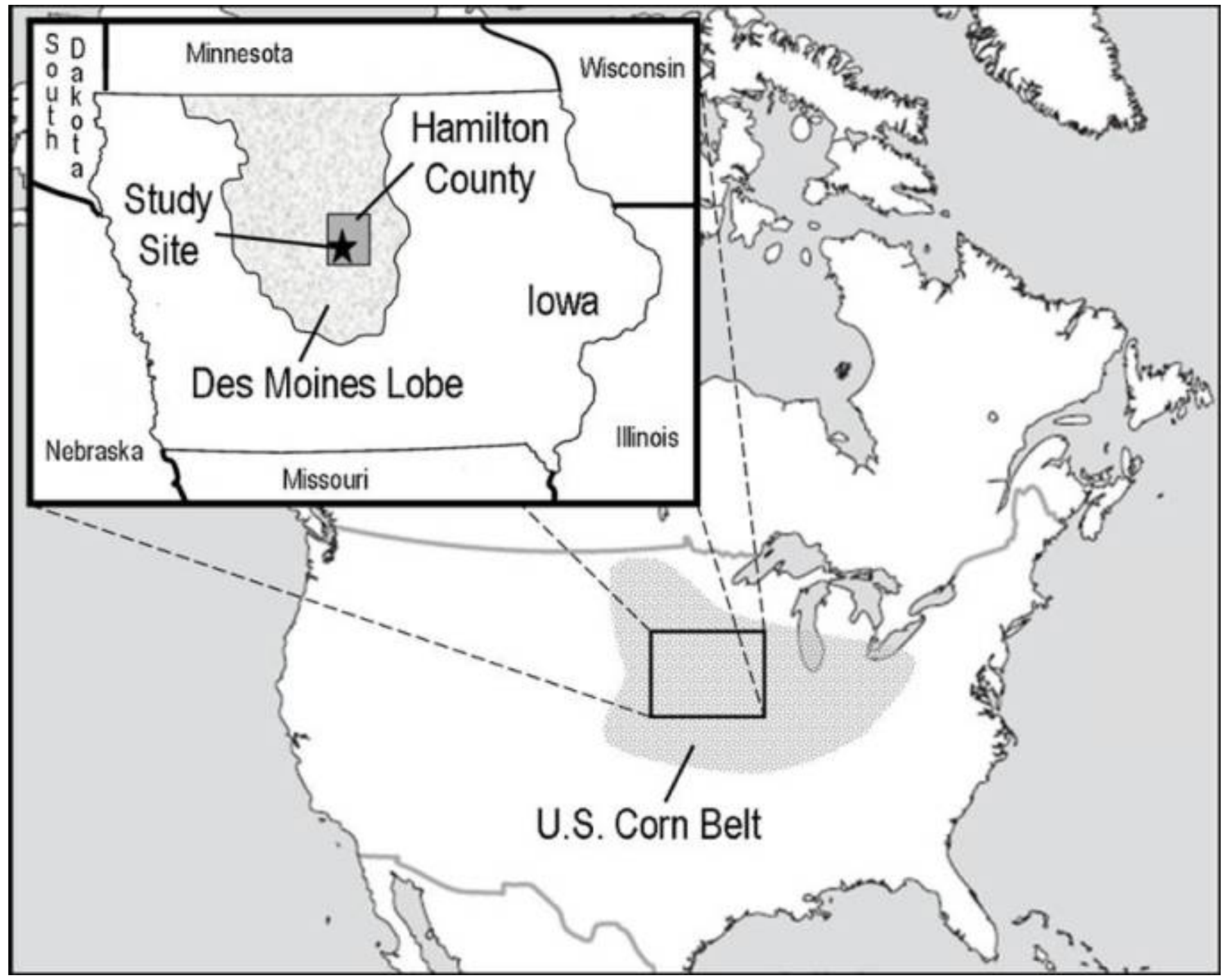

During initial visits to gathering places in our study site, we found that the local people were suspicious of our intentions and reluctant to talk. A breakthrough came when a group of local women took an interest in our research project and volunteered contact information for several local farmers, some of whom were their family members. Thanks to their referral, several farmers consented to be interviewed. These interviewees helped us choose other subjects who were representative of groups that we wished to interview. With the help of a local name and reference, scheduling interviews became much easier. In the end, only three people whom we asked to participate in in-depth interviews declined to talk to us.

\section{Ethnographic in-depth interviews}

Interviews followed an open-ended guide that worked as follows: Although similar questions were asked and similar topics were covered, the exact 
Table 1. Characteristics of Hamilton County as compared to the average of all 15 Iowa counties located entirely or nearly entirely within the Des Moines Lobe geologic formation (USDA 2002, EWG 2006).

\begin{tabular}{lcc}
\hline \hline Characteristic (values for 2002 unless noted) & Hamilton County & Lobe average \\
\hline Hectares & 149,365 & 145,949 \\
Total land in farms (\%) & 94 & 95 \\
Cropland (\%) & 89 & 88 \\
Land in harvested corn and soybeans (\%) & 84 & 82 \\
Land in perennial cover types (\%) & 9 & 9 \\
Land in government conservation programs (\%) & 2 & 2 \\
Cattle and calves sold (number) & 5701 & 16,564 \\
Hogs and pigs sold (number) & $1,270,158$ & 556,630 \\
Average size of farm (ha) & 177 & 175 \\
Median size of farm (ha) & 96 & 107 \\
Farms (number) & 797 & 790 \\
Corn and soybean subsidies 2005 (U.S. \$) & $26,582,426$ & $24,581,155$ \\
Conservation subsidies 2005 (U.S. \$) & $1,913,244$ & $1,619,051$ \\
\hline
\end{tabular}

wording and flow of questions varied between interviews. Interviews included three sections. The first section began with the broad question, "What is most important to you about the rural countryside?" Here we probed how interview subjects perceived the natural landscape; how they viewed their neighbors, communities, and institutions; what challenges they saw facing their rural area; and what local assets and amenities they most valued. In the second section, we used 14 pictures of Corn Belt agricultural landscapes to elicit the participants' evaluations of different land uses and cover types. Photographs were selected to represent a suite of potential landscape scenarios that varied from maximization of row crop production at one end of the spectrum to a high concentration of perennial conservation practices at the other. We closed each interview by asking interviewees what sources they used for advice and information on agricultural and conservation practices, reviewing important aspects of our conversation, and asking participants to share their visions of what they would like the local landscape to look like $25 \mathrm{yr}$ in the future.

\section{Qualitative data analysis}

Interviews were recorded and transcribed. Transcripts were imported into the NVivo7 data management and analysis software package (QSR 2006). This software package was used as an aid in identifying and developing themes in the data in several ways. Interview data were coded (Miles and Huberman 1994) into descriptive and topical categories by the lead author (Atwell 2008). Some of these categories were determined a priori based on our study questions, whereas others emerged from the data or from comparing and contrasting the data with theoretical considerations. Themes in the data were identified by analyzing the chunks of interview data assigned to different codes in several ways (Ryan and Bernard 2003). Themes reflected recurring concepts expressed by interview subjects 
and were also identified by comparing similarities and dissimilarities in the data; by looking at the use of key phrases, metaphors, and stories; and by sorting and assigning coded data into different hierarchical groupings.

Iterative rounds of analysis were used to further scrutinize how the data reinforced or contradicted themes and with what caveats, as well as how themes were related to one another, to study questions, and to theoretical considerations. Here the text searching, sorting, and crosstab capabilities of the NVivo7 software were used to analyze how parts of interview text assigned to different codes related to one another, to emerging themes, and to various attributes of participant backgrounds (QSR 2006). The second and third authors each read a random, nonoverlapping third of the interviews to ensure that analysis was consistent, valid, and confirmable. All the authors compared coding choices and worked together using triangulation (Neuman 2003, Ryan and Bernard 2003) to develop consensus on the meaning and identifying features of themes in the data. After reaching consensus, transcripts were reread and recoded by the lead author to more thoroughly analyze the agreed-upon themes.

\section{RESULTS}

\section{Interviewee characteristics}

We completed 33 in-depth interviews with 42 subjects. Several interviews were conducted with pairs, usually husband-wife couples. Although these pairs often spoke in unison, in several instances we noted differences in their perspectives that were relevant to our analyses. Interviews lasted an average of 74 min and generally took place in the participants' homes. Eleven of our 42 interviewees were women, and 31 were men; 28 were farm operators, and 14 were nonfarm rural residents. Twenty-six subjects owned farmland, including two nonfarm rural residents and 24 farm operators. Five of the farm operators we interviewed were retired. The majority of the nonfarm rural residents we interviewed worked within our study area, whereas four commuted between 20 and 120 $\mathrm{km}$ to their places of employment. Thirty-seven interviewees were raised in rural areas, and 31 grew up within $20 \mathrm{~km}$ of our study site. Our participants were active in formal and informal civic organizations such as churches, coffee groups, farm and service organizations, municipal boards, and fraternal societies.

The 23 active farm operators we interviewed averaged $51 \mathrm{yr}$ of age, ranging in age from 23 to 64 yr. Of these farmers, 19 received $50 \%$ or more of their household incomes from farming. Farm operations ranged in size from 13 to $1505 \mathrm{ha}$, with an average size of $495 \mathrm{ha}$. The average holding size among farm owners was 157 ha. In total, our interviewees operated or owned 9834 ha of farmland, nearly all of which was planted in corn and soybeans, except for 432 ha (4\%) that had been planted in various forms of perennial cover as part of USDA farm conservation programs. In 2005, each of the farmers interviewed received an average of $\$ 57,015$ in USDA commodity support subsidies and an average of $\$ 5348$ in USDA conservation support payments (EWG 2006). Twelve of our interview subjects owned livestock, eight of these in concentrated animal feeding operations (CAFOs). Two of these CAFOs housed turkeys, and six were devoted to hogs. Turkey operations averaged 38,000 head sold/yr, whereas hog operations ranged in size from 6000 to 47,000 head of animals sold/yr.

\section{Themes and scales}

Through qualitative analysis, we determined that 12 of the themes of moderate strength that emerged from the interview data were the most cogent in addressing our study questions (Table 2). When we considered the inter-relatedness of these themes within and among interviewees, we found a good deal of variation in individual perspectives. However, when taken together, these themes grouped into three strong classes that were consistent across interview subjects: (1) farm compatibility, (2) community reinforcement, and (3) institutional transparency. Each of these classes of themes corresponds to a particular biophysical and social scale (Fig. 2). Although the overlap between analogous biophysical and social scales is not exact, their correspondence emerged from, and was helpful in explaining, interview data. Each of these three classes and their supporting themes are explained below.

\section{Farm compatibility}

Eighteen of the 23 active farmers whom we interviewed indicated that their evaluation of, and 
Table 2. The 12 themes that arose from our interview data arranged into three classes: farm compatibility, community reinforcement, and institutional transparency.

\begin{tabular}{|c|c|c|}
\hline Farm compatibility & Community reinforcement & Institutional transparency \\
\hline $\begin{array}{l}\text { New practices must be compatible } \\
\text { with farm: }\end{array}$ & $\begin{array}{l}\text { Decisions to adopt practices are } \\
\text { reinforced through: }\end{array}$ & $\begin{array}{l}\text { Practices must be supported by programs } \\
\text { and policies that are: }\end{array}$ \\
\hline Priorities & Face-to-face communication & Consistent over time \\
\hline Profitability & Local social networks & Straightforward \\
\hline Practices & Cultural social norms & Flexible \\
\hline Equipment and technology & Local support structures & Carefully targeted \\
\hline
\end{tabular}

willingness to adopt, perennial conservation practices was strongly influenced by how these practices were or were not compatible with their current farm operations. Four themes describe farmers' evaluations of these perennial practices: (1) How did these practices interface with current farm priorities? (2) Would these practices increase or detract from the profitability of their farming operations? (3) Did these practices mesh with their current farm practices? (4) Were these practices compatible with and supported by current farming equipment and technology? Because these four themes overlap, we explain them together below.

Thirty-six of the rural people we interviewed, including both farmers and nonfarm rural residents, offered general approval of perennial conservation practices on marginal agricultural land such as restored wetlands and riparian buffer strips. One farmer, who farmed 324 ha of corn and soybeans, took 27 ha out of production and put it into a federal wetland conservation program because it was poorly drained and routinely experienced flooding. He explained his rationale as follows:

Me and the neighbor lady went up 15 years ago, and it was 300 bucks an acre for another tile line [to provide underground field drainage]. Well, nobody could stand that kind of cost, so we just kind of tabled it, just suffered with it, 'til they came out with the wetlands [federal conservation program] ... Well, one of the neighbors up north here, he was kind of making fun of me one day. I was complaining about all these waterways coming down here, and he goes, "You know, ifyou were smart, you'd put that in wetlands." He said it kind of abusive. And I sat around and thought, "You know, you're right." ... That was the best thing I'd ever done. Oh, I'd had to fight those fields!

Many farmers indicated that new trends in agricultural technology may make the implementation of buffers and wetlands more compatible with their agricultural production strategies in the future. For example, 19 farmers expressed that, with increasing sizes of farm equipment, they wanted to farm long, straight rows and would therefore be in favor of adding extra land to conservation set asides to square their field borders and make the boundaries of the set asides easier to negotiate. In another instance of technology aiding conservation, five farmers mentioned that precision agriculture using GPS helped them to better identify which lands were worth planting and which were better left out of production.

Three interview subjects voiced approval and 14 voiced distaste for perennial cover in the form of more diverse cropping rotations or strip intercropping on productive agricultural land. Those who expressed negative viewpoints toward these practices saw them as more appropriate for landscapes with greater topographical complexity than is found in the Des Moines Lobe physiographic 
Fig. 2. Analysis of interview data reveals a correspondence between three key biophysical scales and overlapping social scales (Atwell 2008). Corn Belt social-ecological systems are configured at multiple scales with a strong infrastructure to support increased row crop production while providing only a fraction of the comparable support for conservation practices. Analysis of the responses of our interview subjects shows that successful diffusion of perennial conservation practices must consider the socialecological context surrounding practices at multiple scales including: consistent, straightforward, flexible, and carefully targeted incentives and regulations; reinforcement through social networks, norms, and support structures; and compatibility with farm priorities, profitability, practices, and technologies. These are many of the same factors that are currently arranged to support increased row crop production of corn and soybeans.

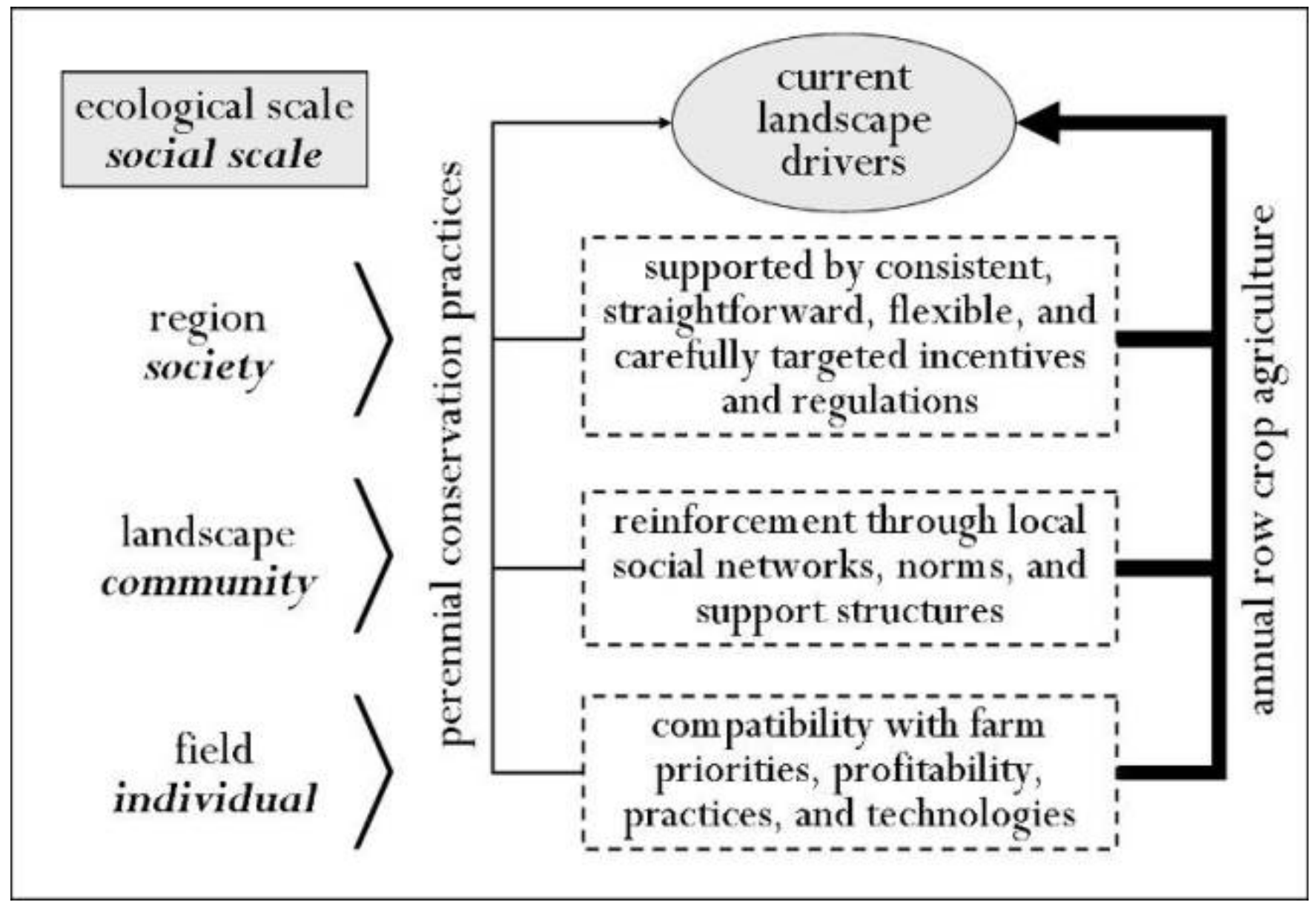

region. Several farmers mentioned that changes in equipment, difficulties in applying herbicides and pesticides, and decreases in crop productivity associated with more diverse systems were an impractical burden that had more implicit costs than pay offs. Ten farmers volunteered that, if it were profitable, they would grow a monoculture perennial such as switchgrass.
Thirty-three interviewees, including both farmers and rural residents, emphasized that conservation practices were not cheap to implement and that farmers needed monetary incentives to make them feasible. One farmer, who operated his family's 445-ha corn and soybean farm, had recently added 40 ha of the estate to a federal wetland conservation program. This is how he explained his decision: 
Well, they [the federal government] paid us. If they didn't pay us, we wouldn't have done it ... Well, I think these [conservation set aside] programs are a good thing, but they'll never happen unless there is a government program paying you to do it. You can't afford to pay $\$ 4000$ per acre for land and then let it sit there and look pretty; you can't do it.

Eight farm operators and owners emphasized that, because of changing land tenure, financial incentives to place farm land in conservation programs often benefit the land owner rather than the farm operator. This is because some federal farm programs, such as the Conservation Reserve Program, give a direct payment to farm owners for taking land out of production. When other programs such as the Conservation Security Program give a direct payment to farm operators for conservation practices, land owners often raise the cash rent paid by the operator who farms the land to capitalize on this form of income. This is problematic because, on any given farm, either the farm owner or operator may have a more intimate connection with the land and be the primary catalyst of a conservation decision. The comments of two farmers who rent most of their farm ground summarized this problem. The first one said, "You want to remember that ... $50 \%$ or more of the land in Iowa is owned by people who do not farm. And it's growing more all the time. Outside investors are coming in. And so the people that are farming the land and responsible for caring for the land don't own it." According to the second,

Every time we do that [adding land to federal conservation programs], it takes ground out of what we are farming. I actually talked a landlord into putting nine acres in CRP [Conservation Reserve Program] last year. Land that one year you grow bumper crop, the next year you drown out ... So she put another nine acres in, which took money out of my pocket. I don't get any income off that land anymore. Some of that stuff you just do ... I would have liked to have seen me get some benefit out of doing that ... I did all the leg work to make it happen. I offered to do it 'cause, in the long run, I thought it was going to benefit the ground and benefit everybody involved.

The latter of these two quotes illustrates the struggle to balance competing priorities, which in this case were income, time, ethics, and norms, that was voiced by many farmers when describing conservation decisions. Thirty-four of the rural people with whom we spoke stressed that it is increasingly difficult to make a living through farming. Adopting a new agricultural practice takes a good deal of time, effort, and risk. Farmers emphasized that, although they may have approved of a practice, its implementation must compete with a number of other farm priorities. Many farmers told us stories about the challenge of continuing to run a profitable operation despite the decreasing profit margin per unit of land and the increasing competition for land among operators looking to expand their operations to maintain profits. With only a decade or so until they retire and with no one to take over the farm after they are finished farming, seven of the farmers we interviewed indicated that they are not looking to make innovative changes in their farming or conservation practices. A 64-yearold farm owner and operator said, "We're at the edge where we don't know whether to quit or wait. I got one boy that lives in Sioux Rapids, and [pause] he's got a nice house, a wife, a family. I can't really encourage much; he kind of has to decide on his own ... I'd quit today if he'd come back and farm."

\section{Community reinforcement}

Four themes describe the ways in which participant evaluations of perennial conservation practices hinge upon relationships with members of their local communities: (1) face-to-face communication, (2) local social networks, (3) cultural social norms, and (4) local support structures. As described in our methods, face-to-face communication and the use of local social networks were crucial in gaining entry into our study site, and interview data demonstrate that cultural norms and communitylevel support systems play an important role in shaping both agricultural and conservation decisions.

During interviews, 15 of the people we talked to volunteered that some form of face-to-face communication, similar to that involved in in-depth interviews, is essential for increasing public understanding and acceptance of perennial conservation practices. Several farmers also indicated that the conversational approach involved in our in-depth interviews made the experience more valuable than they had expected. One comment from a farmer with extensive holdings in corn, soybeans, and hogs summarized the change in 
attitude that we often encountered over the course of the interviewing process:

I think the most important thing is doing
just what we're doing, talking about it
[pause] ... for us to understand where
you're coming from and the job you're
trying to do, andfor you to understand, from
a practicality standpoint, what works and
doesn't work ... [long pause] Because if we
can't ... I don't mean to set this up as we're
two opposing sides, Idon't mean that at all,
but in doing what you're trying to do or
trying to understand, and in working with
us, I mean, the first thing is to sit down and
have a dialogue. You know, without that
you're never going to accomplish anything
...

Community-level social connections were expressed as very important to rural stakeholders. Thirty interviewees emphasized, and all other subjects discussed, the importance of their neighbors, social networks, and rural communities. Declines in the number of people on the land, in rural social cohesion, and in community commerce and vitality were often mourned. Thirty-eight interviewees made comments illustrating ways in which compliance with cultural norms are monitored, praised, and/or sanctioned. Their viewpoints illustrate that our interview subjects scrutinize their neighbors' practices and are influenced by their neighbors' opinions. Another farmer, with extensive holdins in corn, soybeans, and hogs, described interactions with his nonfarm neighbors: "And I've had two people that own acreages that I farm land around. When I sprayed this last time, they came out and talked to me as I was leaving the field ... And they thanked me for coming to their farm when the wind was blowing away from the acreage."

Two other livestock farmers emphasized that, with rising rural tensions over livestock odor, it is increasingly important that farm operators invest in relationships of mutual understanding with their neighbors. Recall also how, in the first quotation in the previous section, two neighbors are included in the account of that farmer's decision to put land in a conservation program, one of whom had expressed an influential, socially normative point of view.

Through ethnographic and interview data, we were able to identify social networks comprising the interconnected relationships between community members and centered around gathering spots and events that were consistently referred to across interviews. These networks, places, and events were voiced as important in brokering information related to both agriculture and conservation land use. For example, one such location, which emerged as both a gathering/coffee spot as well as a hub of farming information, was a business that sold agricultural supplies and chemicals. This business employed community members and farmers in a number of different capacities, including the role of trained agronomists. These agronomists were trained by national agribusiness corporations to disseminate technical information about their products and related farming advice to their farmer peers at a local level. Fifteen of the active farmers we talked to indicated that local agronomists such as these were their primary source of farm advice, despite the fact that nine of these same farmers, in addition to seven other active farmers, five retired farmers, and nine nonfarm rural residents, expressed concern about the encroachment of corporate control on local farming. Although they may voice suspicion with regard to this external corporate control over local agricultural practices, our interviewees were generally willing to trust the agronomists' advice because of their peer connection.

Similar to their role in the transfer of information about practices related to production agriculture, social connections were also voiced as a key factor in disseminating information about, and facilitating the adoption of, conservation practices. Six farmers who had positive experiences with conservation programs mentioned the helpful nature of conservation personnel, whereas eight others suggested that a lack of connection with local agents was one reason they were frustrated with, or unwilling to implement, conservation programs. The owner and operator of a 178-ha corn and soybean farm was proud that a local conservation agent had come to his farm and given him a positive evaluation of his tillage practices: "He praised me for the residue I had up at the time. He told me I was doing a good job ... It's nice that he has more of a laid-back approach and tries to work with people rather than just standing up and telling them. That can turn you off."

One of our interviewees, who had grown up and still farmed in our study site, had also worked at a local level in conservation agencies for several decades and was referred to as a respected local leader by 
several other interview subjects. Based on his experience working with conservation initiatives in and around our study site, this agent summed up the sentiments of many of our interviewees:

That farmer-to-farmer contact ... is so important... It's hard for them to go out and replace a piece of equipment and totally change their practices... There's a big learning curve there. But if you can get farmer-to-farmer or neighbor-to-neighbor talking and then to have the technical support from the government ... [That is how] you put it onto their level where it means something to them, onto their land that they manage.

\section{Institutional transparency}

When viewing photographs of perennial conservation practices, many farmers expressed strong and mixed emotions about the nature of governmental farm conservation programs. From the perspectives of our interviewees, four themes describe the characteristics of conservation programs that would increase the success of perennial conservation practices: (1) consistency over time, (2) straightforwardness, (3) flexibility, and (4) careful targeting.

Twenty-seven of our interview subjects expressed some sort of general suspicion of the government, and eight of the active farmers with whom we spoke volunteered that they were not fond of government commodity subsidies that rewarded corn and soybean production. One farmer's comments echo the sentiments of other participants: "Well, shoot, I'd just as soon all my income came from the open market. Then I wouldn't have to deal with the government at all. That would be the best thing ever." On a pragmatic level, however, many farmers had worked with the complexities of the commodity subsidy programs for several years and spoke of these programs as a routine part of rural life.

Twenty-five of the farmers we interviewed favored a hypothetical transition to "green payments" that would provide government support to farmers to implement restoration projects on marginal agricultural land. At the same time, 16 of these farmers admitted that they were hesitant to express support for, and participate in, these green conservation programs because of three main factors. First, 10 farmers complained about the changing and ephemeral nature of government conservation programs. One farmer talked about these programs in this way, "I don't see anything wrong with any of them ... I just, after that 10-year program, I just don't trust the government. You don't know what they'll do. They'll flip-flop on you." Second, 10 farmers mentioned the complexity and hassle of working with the conservation programs, and, third, 14 farmers voiced a general resistance to regulation. Many of these interviewees advocated for greater flexibility in farm conservation programs so that they could be adapted to the particularities of different farms and farming operations. One large corn, soybean, and hog producer wrestled with his feelings about government regulation in this way:

Well, ideally we'd get paid for stuff we're doing without having to jump through all the hoops to do it. But ... the guys that write the programs and come up with these ideas are in a tough spot. They've got to write it so they're sure the people that deserve it are the ones that are getting it ... You have to build in safeguards to protect against fraudulent application and fraudulent acceptance of payments that you really haven't earned.

Two local leaders, one in conservation and the other in politics, were concerned about the lack of funding for conservation programs. They emphasized the need to carefully target how limited conservation funds are spent and to direct dollars, personnel, and practices to critical locations across landscapes. Both thought that agricultural and environmental technologies would make this process more feasible in the future. One of these leaders put it this way:

I believe, and very firmly, that into the ... very short future, conservation technicians are going to have to get extremely sharp about what they are doing - the technology is there-and not overdesign things. Target, target, target. Don't waste your money. Target it.

\section{DISCUSSION}

\section{Stuck in a trap}

Our interview data revealed a discrepancy between what is desired and what is actually considered feasible in terms of current land use in the Corn Belt. Although most interviewees voiced tentative 
approval of more widespread distribution of perennial conservation practices on marginal agricultural land and of green payments to support these practices, the adoption of such practices is not currently a priority within this rural socialecological system.

Diffusion of innovation theory helps us to explain why seemingly beneficial innovations are not adopted. Results of diffusion research indicate that the rate of adoption for an innovation is directly proportional to that innovation's relative advantage, compatibility, trialability, and observability and inversely proportional to its complexity (Rodgers 2003). Examples of these principles abound in our data. Although interviewees perceived perennial conservation practices as having some relative advantages over some current agricultural practices, they suggested that these practices exhibit low compatibility with their current farm priorities, profitability, practices, and technologies in comparison to growing more corn and soybeans. Perennial conservation practices may also have high initial implementation costs and are often long term, making them difficult to adopt on a trial basis when compared to, for instance, trying a new variety of seed corn or fertilizer.

In addition, as operators compete against one another for land to farm, they often find themselves paying high rents to the owners of the land and therefore make little profit per land unit. This increases the pressure on operators to farm more ground, which means that prompting the owners to put land in conservation programs is neither profitable nor a priority. Interview data also show how agribusiness corporations are heavily invested in the growth of row crop agriculture through franchises and salespersons that are well integrated into local communities and social networks. In contrast, conservation agencies and personnel are only partially or weakly connected to these same communities and networks. Interview subjects viewed conservation practices and their attendant government support packages as more complex and less reliable than growing corn and soybeans under current incentive programs for commodity production. This is in part because the structure of commodity programs has been largely consistent for several decades, whereas conservation programs have changed a great deal over time.

These examples illustrate how the adoption of perennial conservation practices is currently impeded within the social-ecological system of the Corn Belt at multiple scales (Fig. 2). Resilience theory suggests that systems rich in natural and external resources, such as the high-input row crop systems found in the Corn Belt, can function in ways that appear optimum during periods of productivity and growth while simultaneously losing their ability to adapt to unforeseeable change and crisis. When an extremely rich system loses the dynamic character that allows it to respond to the normal adaptive cycles of growth, collapse, reorganization, and exploitation, it can become locked in a static configuration referred to as a rigidity trap (Gunderson and Holling 2002). Despite social and ecological dysfunction, systemic resilience to external perturbations can remain high, although its nature becomes more akin to a static engineered resilience than to dynamic ecological resilience.

Many aspects of the current Corn Belt system seem to be locked into just such a static trap. Despite declines in other social and ecological components of this system, agricultural growth continues to be reinforced by rich internal resources that include deep glacial soils, temperate climate, and social connectedness as well as external inputs such as government subsidies for commodity production, agribusiness investments in local community networks, energy from fossil fuels, nutrients, pesticides, herbicides, and agricultural technologies (Duffy 2006, Nassauer et al. 2007). Although perennial conservation practices may be one tool to help restore ecological function to this system, its sociocultural and political aspects are not currently compatible with the adoption of these practices.

\section{Innovation across scales}

Conservation practices are "preventative innovations" that often lack immediate profitability but are adopted on the grounds that they will alleviate future problems (Rodgers 2003). For this reason, their effects have a high degree of uncertainty, and there has been debate, much of it centered in the Corn Belt, as to whether "classic" diffusion theory can be applied to conservation innovations (Nowak 1983, van Es 1983, Fliegel and Korsching 2001). The perspectives taken by scientists on both sides of the debate suggest that a greater understanding of attendant political, social, and ecological contexts is crucial to understanding the mechanisms by which preventative innovations are adopted. 
Resilience theory suggests that feedback loops between social and ecological processes acting at different spatial and temporal scales can constrain or enhance the potential for innovation within the system. Interview data suggest that the adoption of conservation practices is not contingent upon a simple or single factor such as economic profitability or effective government conservation legislation. Rather, landscape-scale adoption of perennial conservation practices must be compatible with ecological, sociocultural, economic, and political aspects of Corn Belt systems at multiple scales.

Analysis of our interview data leads us to posit that farmer adoption of perennial conservation practices is contingent upon the compatibility of these practices with other aspects of the system at three key scales (Fig. 2). At an individual/farm scale, conservation practices must be compatible not only with farm profitability but also with current farm priorities, practices, and technologies. Our data also illustrate how interpersonal communication through relatively local social networks and normative cultural signals mediate the way in which our interviewees made decisions about their landscapes. The extent to which government programs are seen to be consistent, long term, straightforward, and adaptable to their farm operations also has a great impact on whether or not farmers are willing to participate in these programs.

Because rural stakeholders view their environs primarily as a "countryside" network of farms and people (Atwell 2008), the mesoscale of the community may play a particularly key role in the Corn Belt system by mediating interactions between macro- and microprocesses. Local conservation agents may be able to use community social networks to broker interactions between variables that have the potential to change in relatively short periods, such as infield land-use practices, and variables that are slower to change, e.g., hydrologic function, rural culture and demographics, and national agricultural policy.

\section{Linking adoption and adaptation}

At the close of the interviews, we asked the participants to tell us what they would most like to see in the countryside of the future. Although many of our respondents initially balked at the question because they considered change unlikely or had trouble conceiving of a future that was different from the present, some went on to display a great deal of creativity in their answers. We consider their answers creative because they synthesized or elucidated concepts that were discussed earlier in the interview in new and unexpected ways. Having already viewed and discussed photos of Corn Belt landscapes, many of which depicted various perennial conservation practices, several of the creative futures envisioned by interviewees linked conservation practices to other aspects of the countryside that they had indicated were important to them at the beginning of their interviews. For example, the operator of a large corn, soybean, and hog farm summarized what he considered to be the most important themes of our interview in this way:

Number one, keep the farm families on the land. Number two, the technology that is coming is not going to get any smaller, it's just going to keep booming ... and I think that's a positive. [pause] And the environmental side of it is not going to go away ... You could draw arrows between these three and just make it a big circle, because the technology is going to help on the environmental side. The environmental side-the farm families want to keep the environment protected as much as they can because they're out here, living in that area. And in order for the farm families to stay out here, they're going to have to utilize the technology. Because if the farmfamily can't be productive, then they're going to have to get offfarm jobs, which means they're going to get pushed back to the city.

For these reasons, we deem that creative integration of perennial conservation practices into ideal futures was based on a genuine process of social learning (Plummer and FitzGibbon 2007) though interviews. Some of the strongest positive comments about conservation practices came only after interviewees had had time to consider and talk through the connections between these innovative practices and other aspects of the systems in which they lived. Our interview data indicate that future adoption of perennial conservation practices will not hinge upon a simple economic, political, or technocratic fix at any one scale of the system, but rather on the collective adaptation of social actors across multiple scales and through collaborative learning. 


\section{CONCLUSION}

Social-ecological systems in the U.S. Corn Belt are currently trapped in a static configuration by the convergence of factors across several scales. These factors make system change, including the increase of perennial cover on the landscape, difficult. However, the emerging bioeconomy ushers in a time of reorganization and uncertainty, creating the potential for long-term change in key system structures. The successful adoption of perennial conservation practices depends upon the adaptation of sociocultural and political structures at multiple scales within Corn Belt systems, and initiatives that focus on the optimization of outcomes at only one scale are not likely to result in widespread adoption or in long-term and lasting change. The scales that seem to be limiting in this system are highly social in nature and include cultural as well as spatial and temporal components. In particular, the community scale arose repeatedly in our data as playing an important role in mediating the interactions between individual decisions about private property and regional outcomes encouraged by government incentives and regulations. Our research suggests that an increase in interpersonal contact between conservation agents and potential adopters of conservation practices may play a key role in brokering information across scales and in bridging differences in perception. Such collaborative learning has the potential to harness the adaptive capacity of regional social actors and to bolster the ecological resilience of Corn Belt agricultural systems.

Responses to this article can be read online at: http://www.ecologyandsociety.org/voll4/iss1/art30/ responses/

\section{Acknowledgments:}

We thank our interviewees for their honesty and insight. We also thank Terry Besser, Tricia Knoot, Kris Atwell, and two anonymous reviewers for comments that improved earlier drafts of this manuscript. Megan Boyd, Carrie Eberle, Luke Gran, Bonnie Jan, Anna MacDonald, and Krystina Smith provided assistance with interview transcription and analysis. This research is funded by the Leopold Center for Sustainable Agriculture, USDA Sustainable Agriculture Research and Education (SARE), the U.S. Forest Service Northern
Research Station, and Iowa State University's Department of Natural Resource Ecology and Management and Graduate Program in Sustainable Agriculture.

\section{LITERATURE CITED}

Atwell, R. C. 2008. Perennial vegetation, human adaptation, and the resilience of linked socialecological systems in the U.S. Corn Belt. Dissertation. Iowa State University, Ames, Iowa, USA.

Axelrod,D.I. 1985. The rise of the grassland biome, central North America. Botanical Review 51:163-201.

Burt, R. S. 1999. The social capital of opinion leaders. Annals of the American Academy of Political Sciences 566:37-54.

Christensen, L. M. 2008. Perceptions of change in southwest Yukon land and socialscapes: implications for the study of cumulative effects and social thresholds. Thesis. University of Alberta, Edmonton, Alberta, Canada.

Coleman, J., E. Katz, and H. Menzel. 1957. The diffusion of an innovation among physicians. Sociometry 20:253-270.

Cumming, G. S., D. H. M. Cumming, and C. L. Redman. 2006. Scale mismatches in socialecological systems: causes, consequences, and solutions. Ecology and Society 11(1): 14. [online] URL: http://www.ecologyandsociety.org/vol11/iss1/ art14/.

Duffy, M. 2006. The changing structure of agriculture. Available online at: http://www.econ.i astate.edu/faculty/duffy/pages/powerpoint/ Changingstructureag.ppt.

Environmental Protection Agency (EPA). 2007. Hypoxia in the northern Gulf of Mexico: an update by the EPA Science Advisory Board. EPA Science Advisory Board, Washington, D.C., USA. Available online at: http://yosemite.epa.gov/sab/SA BPRODUCT.NSF/C3D2F27094E03F90852573B8 00601D93/\$File/EPA-SAB-08-003complete.unsigned. pdf. 
Environmental Working Group (EWG). 2006. Farm subsidy database. EWG, Washington, D.C., USA. Available online at: http://www.ewg.org/farm/

Fliegel, F. C., and P. F. Korsching. 2001. Diffusion research in rural sociology: the record and prospects for the future. Social Ecology Press, Middleton, Wisconsin, USA.

Gunderson, L. H., and C. S. Holling, editors. 2002. Panarchy: understanding transformations in human and natural systems. Island Press, Washington, D.C., USA.

Handwerker, W. P. 2005. Sample design. Available online at: http://anth.uconn.edu/faculty/h andwerker/375QEreadings/Handwerker.pdf.

Harrison, N. 2003. Good governance: complexity, institutions, and resilience. Available online at: htt p://sedac.ciesin.columbia.edu/openmtg/docs/Harrison. pdf.

Hatfield, J. L., L. D. McMullen, and C. S. Jones. 2009. Nitrate-N patterns in the Raccoon River Basin related to agricultural practices. Journal of Soil and Water Conservation 64(2): in press.

Hinkamp, D., T. Borich, J. Euken, and S. Devlin. 2007. County bioeconomy discussion results. Iowa State University Extension, Ames, Iowa, USA.

Jannsen, M. A., M. L. Schoon, W. M. Ke, and K. Borner. 2006. Scholarly networks on resilience, vulnerability and adaptation within the human dimensions of global environmental change. Global Environmental Change 16:240-252.

Keeney, D., and L. Kemp. 2002. A new agricultural policy for the United States. Minnesota Project, St. Paul, Minnesota, USA. Available online at: http://www.mnproject.org/pdf/A\%20New\% 20Agriculture\%20Policy \%20for\%20the\%20U.S.\% 20by\%20Dennis\%20Keeney\%20\%20Lo..pdf.

Liu, J., T. Dietz, S. R. Carpenter, M. Alberti, C. Folke, E. Moran, A. N. Pell, P. Deadman, T. Kratz, J. Lubchenco, E. Ostrom, Z. Ouyang, W. Provencher, C. L. Redman, S. H. Schneider, and W. W. Taylor. 2007. Complexity of coupled human and natural systems. Science 317:1513-1516.

Miles, M. B., and A. M. Huberman. 1994. Qualitiative data analysis: an expanded sourcebook.
Second edition. Sage Publications, Thousand Oaks, California, USA.

Nassauer, J. I., M. V. Santelmann, and D. Scavia, editors. 2007. From the Corn Belt to the Gulf: societal and environmental implications of alternative agriculture futures. Resources for the Future Press, Washington, D.C., USA.

Neuman, W. L. 2003. Social research methods: qualitative and quantitative approaches. Allyn and Bacon, Boston, Massachusetts, USA.

Nowak, P. J. 1983. Adoption and diffusion of soil and water conservation practices. Rural Sociologist 3:83-91.

Plummer, R., and J. FitzGibbon. 2007. Connecting adaptive co-management, social learning, and social capital through theory and practice. Pages 38-61 in D. Armitage, F. Berkes, and N. Doubleday, editors. Adaptive comanagement: collaboration, learning, and multilevel governance. University of British Columbia Press, Vancouver, British Columbia, USA.

Pritchard, L. J., and S. E. Sanderson. 2002. The dynamics of political discourse in seeking sustainability. Pages 147-172 in L. H. Gunderson and C. S. Holling, editors. Panarchy: understanding transformations in human and natural systems. Island Press, Washington, D.C., USA.

QSR. 2006. NVivo7. QSR, Doncaster, Australia.

Rodgers, E. M. 2003. Diffusion of innovations. Free Press, New York, New York, USA.

Ryan, B., and N. C. Gross. 1943. The diffusion of hybrid seed corn in two Iowa communities. Rural Sociology 8:15-24.

Ryan, G. W., and H. R. Bernard. 2003. Techniques to identify themes. Field Methods 15:85-109.

Schulte, L. A., M. Liebman, H. Asbjornsen, and T. R. Crow. 2006. Agroecosystem restoration through strategic integration of perennials. Journal of Soil and Water Conservation 61:164A-169A.

Secchi, S., J. Tyndall, L. A. Schulte, and H. Asbjornsen. 2008. Raising the stakes: high crop prices and conservation. Journal of Soil and Water Conservation 63:68A-73A. 
Spradley, J. P. 1979. The ethnographic interview. Holt, Rinehart, and Winston, Austin, Texas, USA.

USDA. 2002. 2002 census of agriculture. U.S. Department of Agriculture, National Agricultural Statistics Service, Washington, D.C., USA. Available online at: http://www.nass.usda.gov/Census of Agriculture/index.asp.

Walker, B., S. Carpenter, J. Anderies, N. Abel, G. Cumming, M. Jannsen, L. Lebel, J. Norberg, G. D. Peterson, and R. Pritchard. 2002. Resilience management in social-ecological systems: a working hypothesis for a participatory approach. Conservation Ecology 6(1):14 [online] URL: http:/ /www.ecologyandsociety.org/vol6/iss1/art14/print. pdf.

Walker, B., D. Salt, and W. Reid. 2006. Resilience thinking: sustaining people and ecosystems in a changing world. Island Press, Washington, D.C., USA.

Wejnert, B. 2002. Integrating models of diffusion of innovations: a conceptual framework. Annual Review of Sociology 28:279-326.

Westley, F., S. R. Carpenter, W. A. Brock, C. S. Holling, and L. H. Gunderson. 2002. Why systems of people and nature are not just social and ecological systems. Pages 103-120 in C. S. Holling and L. H. Gunderson, editors. Panarchy: understanding transformation in human and natural dystems. Island Press, Washington, D.C., USA.

van Es, J. C. 1983. The adoption/diffusion tradition applied to resource conservation: innapropriate use of existing knowledge. Rural Sociologist 3:76-82. 